\title{
Promoting wellness and stress management in residents through emotional intelligence training
}

This article was published in the following Dove Press journal:

Advances in Medical Education and Practice

\section{Ramzan Shahid' \\ Jerold Stirling' \\ William Adams ${ }^{2}$}

'Department of Pediatrics, Stritch School of Medicine, Loyola University Medical Center, Maywood, IL, USA; ${ }^{2}$ Clinical Research Office Biostatistics Core, Loyola University Chicago, Maywood, IL, USA
Correspondence: Ramzan Shahid Department of Pediatrics, Stritch School of Medicine, Loyola University Medica Center, 2160 S. First Ave, Maywood, IL 60153, USA

Tel +l 7083279125

Fax + I 7083279132

Email rshahid@lumc.edu
Background: US physicians are experiencing burnout in alarming numbers. However, doctors with high levels of emotional intelligence (EI) may be immune to burnout, as they possess coping strategies which make them more resilient and better at managing stress. Educating physicians in EI may help prevent burnout and optimize their overall wellness. The purpose of our study was to determine if educational intervention increases the overall EI level of residents; specifically, their stress management and wellness scores.

Participant and methods: Residents from pediatrics and med-ped residency programs at a university-based training program volunteered to complete an online self-report EI survey (EQ-i 2.0) before and after an educational intervention. The four-hour educational workshop focused on developing four EI skills: self-awareness; self-management; social awareness; and social skills. We compared de-identified median score reports for the residents as a cohort before and after the intervention.

Results: Thirty-one residents ( 20 pediatric and 11 med-ped residents) completed the EI survey at both time intervals and were included in the analysis of results. We saw a significant increase in total EI median scores before and after educational intervention ( $110 \mathrm{vs} 114, P=0.004)$. The stress management composite median score significantly increased ( $105 \mathrm{vs} 111, P<0.001)$. The resident's overall wellness score also improved significantly (104 vs $111, P=0.003$ ).

Conclusions: As a group, our pediatric and med-peds residents had a significant increase in total EI and several other components of EI following an educational intervention. Teaching EI skills related to the areas of self-awareness, self-management, social awareness, and social skill may improve stress management skills, promote wellness, and prevent burnout in resident physicians Keywords: burnout, physician, educational intervention

\section{Introduction}

Burnout is defined as a syndrome characterized by overwhelming exhaustion, feelings of cynicism and detachment from work, and a sense of ineffectiveness and lack of accomplishment. ${ }^{1}$ The number of physicians experiencing burnout in the US has reached alarming numbers, with recent data indicating a rate of at least $50 \% .{ }^{2}$ Unfortunately, it appears that physicians are exposed to stressors contributing to burnout early in their training. The rate of burnout in resident physicians has been reported at $50 \%$ and may be as high as $75 \%$ in some specialties. ${ }^{3}$

Individuals with high levels of emotional intelligence (EI) may be protected from developing burnout, as they possess more effective coping strategies that enable them to be more resilient and manage stress better. ${ }^{4}$ Therefore, developing the EI skills of physicians-in-training may help prevent burnout and optimize their overall wellness. ${ }^{5}$ 
These skills may also serve as lasting tools that prevent burnout later on in their careers. The Accreditation Council for Graduate Medical Education has created new common program requirements focused on improving well-being and preventing burnout in resident physicians. ${ }^{6}$ In attempting to satisfy these new directives, we implemented an EI curriculum for our resident trainees.

Educational interventions have been shown to improve resident EI skills. ${ }^{7,8}$ The EI model emphasizing the four components of self-awareness, self-management, social awareness, and social skill is commonly accepted., ${ }^{9,10}$ Selfawareness involves knowing yourself by being aware of your emotions eg, what satisfies you, frustrates you, annoys you, or angers you. Self-management relates to the ability to manage your emotional reactions to situations and people. Social awareness comprises the ability to accurately pick up emotions in other people. Social skills are the ability to use awareness of your emotions and those of others to manage interactions successfully.

The purpose of our study was to determine if an educational intervention using this EI model increased the overall EI level of our residents; specifically, their stress management and wellness scores.

\section{Participants and methods}

Residents from the pediatric and med-peds Residency Programs at our university-based hospital volunteered to complete an online, self-assessment, EI survey. The survey tool used was the Bar-On Emotional Quotient Inventory 2.0, EQ-i 2.0®, ${ }^{11}$ administered by the consulting firm of Xcellero Leadership Inc. (Naperville, IL, USA). The survey is an online, 133 item self-assessment instrument that uses a five-point Likert scale to measure EI on five composite scales and 15 content subscales. All scores are normalized to a national mean of 100 with a SD of 15 . We chose the EQ-i 2.0® survey as it provides scores for overall EI and its subcomponents, along with scores for the composite scales of stress management and wellness.

Residents first completed the EI survey in May 2015 prior to a proposed educational intervention. After completing the survey, each resident received a detailed report of their EI level, outlining their strengths and suggested areas of improvement. Residents then participated in an educational intervention program by attending two separate twohour educational workshops (total of 4 hours) focusing on developing EI skills. The curriculum integrated Goleman's model of EI and the four components of self-awareness, self-management, social awareness, and social skills. ${ }^{9}$ The workshops were conducted by the principal investigator and mainly consisted of didactic teaching and discussion. During the sessions, each component of EI was defined and example scenarios taken from the book Emotional Intelligence 2.0 $0^{10}$ were discussed. Additionally, pre-existing videos available on the internet that highlighted various aspects of EI were shown to the residents.

The first workshop introduceed EI and strategies to improve self-awareness and self-management skills. Residents were given examples of qualities that a person with self-awareness would exhibit; eg, commitment, passion, humility, and teachability. A video that showed a person lacking self-awareness was viewed and then discussed. Similarly, qualities of a person with strong self-management skills were discussed, ie, self-control, self-discipline, integrity, and honesty. A video highlighting the importance of honesty and trust was shown to the residents.

The second workshop provided strategies to improve social awareness and social skills. A video related to misperceiving body language was viewed and discussed. The qualities of listening, respect, service, and selflessness were emphasized during the discussion. Teaching of social skills focused on the attributes of kindness, generosity, and forgiveness. A video demonstrating acts of kindness was shown to underscore the importance of social skills as part of EI.

The first workshop was held in the fall of 2015 and the second workshop was conducted in the spring of 2016. In May 2016, two months after the second workshop, residents voluntarily completed the EQ-i $2.0 \AA$ survey as part of the post intervention assessment.

Prior to completing each of the EI surveys, respondents were asked to provide demographic information including age, gender, post graduate year (PGY) of training, and specialty. A summary EI score report was created for each resident and de-identified score reports generated by the consulting firm were then forwarded to the investigators and used to analyze the results. The study was given exempt status by the Loyola University Health Sciences Institutional Review Board because the study gathered and analyzed anonymous survey data.

\section{Statistical methods}

For each resident, we subtracted the post-intervention EI score from his/her pre-intervention score for all EQ-i 2.0 items. Q-Q plots and box plots were used to assess whether this change score was normally distributed within residency type, gender, and residency year (PGY 1-2 vs other advancement). Because of some non-normality, an exact version 
of the non-parametric Wilcoxon rank sum test was used to determine whether the change score was different between residency type, between gender, and between residency year (PGY 1-2 vs other advancement). In these analyses, Rosenthal's $r$ was used as a standard measure of the effect size ( $r$-value) and a Hochberg correction was used to control the Type one error rate within each EQ-i 2.0 construct.

Among all residents, an exact version of the Wilcoxon signed rank test was used to determine whether there was any significant improvement for each EQ-i 2.0 item. Rosenthal's $r$ was used as a standard effect size while a Holm correction was used to control the Type one error rate within each EQ-i 2.0 construct. Significance ( $P$-values) less than 0.05 were considered statistically significant and each test was two tailed (meaning an effect in either direction was interpreted). Further, $r \leq 0.10$ was considered a small effect, while $r \geq 0.50$ was considered a large effect. All other effect size estimates were considered a medium effect. All analyses were completed using SAS version 9.4 (Cary, NC, USA).

\section{Results}

Precisely 45 residents ( 31 pediatric residents and 14 med-ped residents) completed the EI survey in May 2015, while 46 residents ( 30 pediatric and 16 med-ped residents) took the survey in May 2016. Because a group of senior residents had graduated $(\mathrm{n}=14)$, they were unavailable to take the follow-up survey. Therefore, a total of 31 residents ( 20 pediatric and 11 med-peds residents) were available for the analysis. Due to conflicts in scheduling, 25 of these $31(81 \%)$ attended both educational workshops, three residents attended only one of the workshops, and three residents were not able to attend either of the workshops. Slides of the educational material presented at the workshops were sent to any resident that could not attend both workshops.

Demographic information of the 31 residents analyzed as part of the study revealed that $20(65 \%)$ were pediatric residents and 22 (71\%) were females. Among the residents, 13 advanced from PGY1 year to PGY2 year between assessments, 14 advanced from PGY2 to PGY3 year, three advanced from PGY3 to PGY4 year, and one from PGY4 to PGY5 year.

When we compared change in EI as a function of gender or as a function of advancement by year, we found no statistically significant differences (all $P>0.05$ ). Comparing baseline EI scores of pediatric residents to med-ped residents, we found no difference in the overall EI scores (Median $=113$ vs $110, P=0.97)$. After the educational intervention, we observed that med-ped residents had a significantly larger gain in total EI ( $\mathrm{Mdn}=8$ vs $3, P=0.047, r=0.357$ ), self-perception composite ( $\mathrm{Mdn}=6$ vs $1, P=0.04, r=0.368$ ), emotional self-awareness ( $\mathrm{Mdn}=7$ vs $2, P=0.02, r=0.483$ ), interpersonal composite ( $\mathrm{Mdn}=5-1, P=0.03, r=0.382$ ), and reality testing ( $\mathrm{Mdn}=13$ vs $3, P=0.03, r=0.458)$. (Table 1 ).

Table 2 shows the median pre- and post-intervention scores for overall EI along with all sub-scores. For the 31 residents included in the analysis, we saw a significant increase in total EI median scores before and after the educational intervention ( 110 vs $114, P=0.004, r=0.376$ ). Other sub-scores that significantly increased included: self-regard (104 vs $109, P=0.01, r=0.382$ ); self-expression composite (106 vs $109, P=0.03,0=0.282$ ); independence ( 101 vs 107 , $P=0.03, r=0.334)$; and decision-making composite (112 vs $113, P=0.03, r=0.269)$. The median stress management composite score significantly increased (105 vs $111, P<0.001$, $r=0.510$ ), along with all its subcomponents of flexibility (105 vs $111, P=0.02, r=0.330$ ), stress tolerance (104 vs $110, P=0.003, r=0.449$ ), and optimism ( 103 vs $108, P=0.01$, $r=0.388)$. After the educational intervention, the resident's overall wellness score also significantly improved (104 vs $111, P=0.003, r=0.380$ ).

\section{Discussion}

Previous literature on EI has demonstrated that physicians with higher levels of EI are less susceptible to burnout., ${ }^{4,5,12,13}$ Taking this into consideration, our goal was to teach our residents EI skills that would assist them in preventing burnout during training or later in their career. We based our educational intervention on two concepts. The first was that EI skills of residents may be improved through an educational intervention. ${ }^{7,}$ The second is that the ability to manage one's emotional response to stress may prevent physicians from developing burnout. ${ }^{14}$ Our results demonstrate that we were able to improve the overall EI scores of the residency group as a whole. Interestingly, we observed a stronger influence of the intervention on the med-ped residents, even though the baseline EI scores for both groups were not significantly different. This finding may be related to additional educational and clinical experiences that these residents are exposed to while training in internal medicine. The fact that the same curriculum had different outcomes within two medical specialties warrants further investigation.

Our EI curriculum placed emphasis on improving the self-awareness of our trainees, as this skill has been linked to the ability to manage stress and overall wellness..$^{15}$ Our 
Table I Change in El by specialty status

\begin{tabular}{|c|c|c|c|c|c|}
\hline & \multicolumn{3}{|l|}{ Specialty } & \multirow[t]{3}{*}{$P$-value } & \multirow[t]{3}{*}{ Rosenthal $r$} \\
\hline & $\begin{array}{l}\text { IM-Peds } \\
(n=I I)\end{array}$ & $\begin{array}{l}\text { Peds } \\
(n=20)\end{array}$ & $\begin{array}{l}\text { Total } \\
(n=31)\end{array}$ & & \\
\hline & Mdn (IQR) & Mdn (IQR) & Mdn (IQR) & & \\
\hline Total El & $8(2-14)$ & $3(-2-6)$ & $4(0-8)$ & $0.047^{*}$ & 0.357 \\
\hline Self-perception composite & $6(3-15)$ & I (-4-6) & $3(-2-7)$ & $0.040^{*}$ & 0.368 \\
\hline Self-regard & $5(2-14)$ & $2(-1-6)$ & $3(0-12)$ & 0.138 & 0.327 \\
\hline Self-actualization & $2(0-8)$ & $3(-4-5)$ & $3(-3-8)$ & 0.519 & 0.119 \\
\hline Emotional self-awareness & $7(7-17)$ & $2(-7-7)$ & $4(-4-7)$ & $0.018^{*}$ & 0.483 \\
\hline Self-expression composite & $6(-2-13)$ & $4(-I-7)$ & $4(-2-9)$ & 0.508 & 0.122 \\
\hline Emotional expression & $5(-3-13)$ & $3(-3-9)$ & $3(-3-10)$ & 0.534 & 0.115 \\
\hline Assertiveness & $0(-|1-| 4)$ & $2(-9-6)$ & $0(-10-7)$ & 0.534 & 0.119 \\
\hline Independence & $2(-3-12)$ & $6(2-12)$ & $3(0-12)$ & 0.534 & 0.145 \\
\hline Interpersonal composite & $5(-1-10)$ & $-1(-7-2)$ & I (-4-6) & $0.033^{*}$ & 0.382 \\
\hline Interpersonal relationships & $6(0-11)$ & $-2(-7-3)$ & $0(-5-6)$ & 0.062 & 0.409 \\
\hline Empathy & $5(-3-11)$ & $-2(-7-0)$ & $0(-5-5)$ & 0.062 & 0.385 \\
\hline Social responsibility & $7(-10-11)$ & $2(-7-6)$ & $3(-7-7)$ & 0.320 & 0.182 \\
\hline Decision making composite & $8(1-15)$ & I (-4-8) & $4(-4-8)$ & 0.067 & 0.331 \\
\hline Problem solving & $6(0-12)$ & $2(-6-12)$ & $5(-5-12)$ & 0.684 & 0.175 \\
\hline Reality testing & $13(7-2 \mid)$ & $3(-9-7)$ & $7(-7-\mid 1)$ & $0.030 *$ & 0.458 \\
\hline Impulse control & $0(-6-3)$ & $-2(-8-5)$ & $0(-6-3)$ & 0.830 & 0.041 \\
\hline Stress manage composite & $3(2-13)$ & $6(3-10)$ & $6(2-12)$ & 0.943 & 0.015 \\
\hline Flexibility & $8(0-18)$ & $2(-5-12)$ & $6(-3-14)$ & 0.838 & 0.182 \\
\hline Stress tolerance & $8(0-10)$ & $4(I-I I)$ & $5(0-11)$ & 0.976 & 0.007 \\
\hline Optimism & $0(-3-10)$ & $6(0-14)$ & $5(0-13)$ & 0.838 & 0.149 \\
\hline Wellness & $3(0-10)$ & $6(-2-13)$ & $5(-2-12)$ & 0.752 & 0.059 \\
\hline
\end{tabular}

Note: *Value is statistically significant because $P<0.05$.

Abbreviations: El, emotional intelligence; IQR, Interquartile range; Mdn, median change score; $P$, p-value; $r$, effect size; IM-Peds, med-pediatric residents; Peds, pediatric residents.

Table 2 El scores before and after education intervention

\begin{tabular}{|c|c|c|c|c|}
\hline & $\begin{array}{l}\text { Pre-intervention } \\
\text { (Mdn, IQR) }\end{array}$ & $\begin{array}{l}\text { Post-intervention } \\
\text { (Mdn, IQR) }\end{array}$ & P-value & Rosenthal $r$ \\
\hline Total El & $110(102-115)$ & II4 (I08-123) & $0.004 *$ & 0.376 \\
\hline Self-perception composite & $106(102-114)$ & 112 (106-I19) & $0.016^{*}$ & 0.311 \\
\hline Self-regard & $104(95-106)$ & $109(102-113)$ & $0.012 *$ & 0.382 \\
\hline Self-actualization & 107 (104-II7) & II4 (107-II7) & 0.190 & 0.184 \\
\hline Emotional self-awareness & III (I0I-I22) & III (I04-122) & 0.180 & 0.223 \\
\hline Self-expression composite & $106(94-113)$ & $109(100-115)$ & $0.026 *$ & 0.282 \\
\hline Emotional expression & $108(103-118)$ & $113(103-121)$ & 0.076 & 0.276 \\
\hline Assertiveness & $102(91-109)$ & $105(95-109)$ & 0.996 & 0.001 \\
\hline Independence & $101(90-110)$ & $107(93-113)$ & $0.033 *$ & 0.334 \\
\hline Interpersonal composite & 114 (108-119) & II7 (108-I19) & 0.568 & 0.077 \\
\hline Interpersonal relationships & $105(100-113)$ & $108(103-119)$ & 0.999 & 0.097 \\
\hline Empathy & $113(110-121)$ & $118(110-123)$ & 0.999 & 0.027 \\
\hline Social responsibility & $112(105-119)$ & $115(108-122)$ & 0.999 & 0.058 \\
\hline Decision making composite & 112 (10I-II7) & II3 (104-124) & $0.033^{*}$ & 0.269 \\
\hline Problem solving & $105(90-110)$ & 107 (102-I16) & 0.087 & 0.295 \\
\hline Reality testing & 107 (100-117) & $110(100-120)$ & 0.244 & 0.201 \\
\hline Impulse control & II4 (I05-123) & I I4 (I08-123) & 0.597 & 0.077 \\
\hline Stress management composite & $105(98-I I I)$ & $111(103-123)$ & $<0.00 I^{*}$ & 0.510 \\
\hline Flexibility & $105(96-113)$ & III (I02-I22) & $0.016^{*}$ & 0.330 \\
\hline Stress tolerance & 104 (99-I I0) & II0 (99-120) & $0.003^{*}$ & 0.449 \\
\hline Optimism & $103(95-113)$ & $108(98-118)$ & $0.008 *$ & 0.388 \\
\hline Wellness & 104 (94-I I3) & III (99-II8) & $0.003^{*}$ & 0.380 \\
\hline
\end{tabular}

Notes: Valid for each construct. Median composite scores for each construct are tabled with their IQR in parentheses. *Value is statistically significant because $P<0.05$.

Abbreviations: El, emotional intelligence; IQR, interquartile range; Mdn; mMedian change score; $P$, $p$ value; $r$, effect size. 
intervention improved these EI composite scores of our residents significantly. This finding is consistent with previous literature, which demonstrates that the ability to manage and regulate one's emotional response are critical skills that help individuals effectively control or minimize stress. ${ }^{14,16}$ As wellness and burnout are on opposite ends of a continuum, our success in increasing the overall wellness scores of our trainees may reduce the risk of developing burnout in the future.

Residency training programs may wish to consider incorporating EI education into their curricula, as high EI provides a burnout-buffering effect. ${ }^{12}$ In fact, there may even be an advantage in incorporating self-awareness training into undergraduate medical education. ${ }^{17}$ Our EI curriculum may serve as a prototype for other residency programs that are developing their own approaches to promoting wellness and preventing burnout in their trainees.

\section{Limitations}

Our study has several limitations. We did not create a control group of non-participants in the educational intervention. It is possible that the improvement in scores that we saw is related to factors other than the intervention itself. EI testing alone may have increased self-awareness and stimulated self-motivation among our residents independent of the curriculum. This growth motivation, or tendency of people to grow, motivates them to move beyond their current situations. ${ }^{18}$ The increased EI levels in our residents may have also been due to the maturation effect where normal maturation, life experiences, medical training, or some other variable $^{12}$ affected the participants over time. It is possible the residents in our study may have matured and as a result their EI scores also improved.

Additionally, the same residents took the survey one year apart and the increase in scores observed could be related to a practice effect; where increased post-test performance occurs because subjects have become familiar with the questions. Another limitation of our study is that we only evaluated pediatric and med-ped residents, so the results might not be applicable to other residency specialties. Finally, our program is a small program within a larger academic center. It is possible residents at community hospitals or in larger programs might have different levels of EI and wellness.

\section{Conclusion}

As a group, our pediatric and med-peds residents had a significant increase in total EI and several other components of
EI following an educational intervention. Teaching EI skills related to the areas of self-awareness, self-management, social awareness, and social skill may improve stress management skills, promote wellness, and prevent burnout in resident physicians.

\section{Acknowledgments}

The authors would like to acknowledge the pediatric and medped residents for participating in the study. They would also like to acknowledge Stephanie Benesh at Xcellero Leadership for helping to administer the EQ-I 2.0 survey.

\section{Author contributions}

RS and JS contributed to the conception and design of the study, acquisition of data and interpretation of data. WA was primarily responsible for data analysis and assisted with interpretation of the data. RS, WA, and JS were all involved in drafting the manuscript and revising it critically for important intellectual content and have given final approval of the version to be published.

\section{Disclosure}

The authors report no conflicts of interest in this work.

\section{References}

1. Maslach C, Jackson SE, Leiter MP. Maslach Burnout Inventory Manual. 3rd Alto Palo, editor. CA: Consulting Psychologists Press; 1996.

2. Shanafelt TD, Boone S, Tan L, et al. Burnout and satisfaction with work-life balance among US physicians relative to the general US population. Arch Intern Med. 2012;172(18):1377-1385.

3. Martini Set al. Burnout comparison among residents in different medical specialties. Academic Psychiatry. 2004;28(3):240-242.

4. Mikolajczak M, Petrides KV, Hurry J. Adolescents choosing self-harm as an emotion regulation strategy: the protective role of trait emotional intelligence. Br J Clin Psychol. 2009;48(Pt 2):181-193.

5. Lin DT, Liebert CA, Tran J, Lau JN, Salles A. Emotional intelligence as a predictor of resident well-being. JAm Coll Surg. 2016;223(2):352-358.

6. ACGME Common Program Requirements Section VI with Background and Intent. Available from: http://www.acgme.org/Portals/0/PFAssets/ ProgramRequirements/CPRs_2017-07-01.pdf. Accessed September 9, 2018.

7. Dugan JW, Weatherly RA, Girod DA, et al. A longitudinal study of EI training for Otolayngology residents and faculty. JAMA Otolaryngology. 2014;140(8):720-726.

8. Johnson JM, Stern TA. Teaching residents about emotional intelligence and its impact on leadership. Academic Psychiatry. 2014;38(4): 510-513.

9. Goleman D. Leadership that gets results. Harvard Business Review. 2000:78-90

10. Bradberry T, Greaves J. Emotional Intelligence 2.0. San Diego, CA: TalentSmart; 2009.

11. Bar-On R. Emotional Quotient Inventory 2.0 User's Handbook. Toronto Canada: Multi-Health Systems; 2004.

12. Satterfield J, Swenson S, Rabow M. Emotional intelligence in internal medicine residents: Educational implications for clinical performance and burnout. Ann Behav Sci Med Educ. 2009;14(2):65-68. 
13. Weng HC, Hung CM, Liu YT, et al. Associations between emotional intelligence and doctor burnout, job satisfaction and patient satisfaction. Med Educ. 2011;45(8):835-842.

14. Serwint JR, Bostwick S, Burke AE, et al. The AAP resilience in the face of grief and loss curriculum. Pediatrics. 2016;138(5): e20160791e20160791.

15. Zwack J, Schweitzer J. If every fifth physician is affected by burnout, what about the other four? Resilience strategies of experienced physicians. Acad Med. 2013;88(3):382-389.
16. Ogińska-Bulik N. Emotional intelligence in the workplace: exploring its effects on occupational stress and health outcomes in human service workers. Int J Occup Med Environ Health. 2005;18(2): $167-175$.

17. Shapiro J. Walking a mile in their patients' shoes: empathy and othering in medical students' education. Philos Ethics Humanit Med. 2008; $3: 10$.

18. Maslow A. Toward a Psychology of Being. New York: D. Van Norstrand Co; 1968.

\section{Publish your work in this journal}

Advances in Medical Education and Practice is an international, peerreviewed, open access journal that aims to present and publish research on Medical Education covering medical, dental, nursing and allied health care professional education. The journal covers undergraduate education, postgraduate training and continuing medical education including emerging trends and innovative models linking education, research, and health care services. The manuscript management system is completely online and includes a very quick and fair peer-review system. Visit http://www.dovepress.com/testimonials.php to read rea quotes from published authors.

Submit your manuscript here: http://www.dovepress.com/advances-in-medical-education-and-practice-journal 